\title{
Excess travelling-what does it mean? New definition and a case study of excess commuters in Tyne and Wear, UK
}

\author{
Stuart Barr • Anna Fraszczyk • Corinne Mulley
}

Received: 11 May 2009/Accepted: 23 March 2010 /Published online: 13 April 2010

(C) The Author(s) 2010. This article is published with open access at Springerlink.com

\begin{abstract}
Objective This paper has four main aims. Firstly, to undertake a critical review of existing definitions of excess travel focused on travel to work and hence to present a new definition which takes account of important developments in the public transport literature. This is used as the basis to identify whether excess travellers exist in the journey to work context and to identify differences between excess commuters and non-excess travellers.

Overview This is undertaken using two different methodologies of sample selection and analysis: innovative sample selection using GIS to identify hotspots is compared with destination sampling and for analysis the use of time and cost calculations are compared with generalised cost.

Results The results show that a small number of excess commuters do exist and that whilst these travellers admit to a variety of benefits they can get from travel, most of them are excess travelling voluntarily with many factors are influencing their travel choices.

Conclusion Application of this research is that the better understanding of excess travel phenomenon in daily commute will allow for exploring public transport providers' (PTP) policy to encourage sustainable transport patterns of
\end{abstract}

\footnotetext{
S. Barr · A. Fraszczyk $(\bowtie)$

School of Civil Engineering and Geosciences,

Newcastle University,

Newcastle Upon Tyne NE1 7RU, UK

e-mail: anna.fraszczyk@ncl.ac.uk

S. Barr

e-mail: s.1.barr@ncl.ac.uk

C. Mulley

Institute of Transport and Logistics Studies (ITLS),

Faculty of Economics and Business, The University of Sydney,

Sydney, NSW, Australia 2006

e-mail: c.mulley@itls.usyd.edu.au
}

commuting by meeting travellers' expectations and, in the long run, marketing excess travel time into activity time what potentially might create extra revenue for PTP.

Keywords Excess travelling - Generalised cost .

Excess traveller

\section{Introduction}

Excess travel, identified in some way with travellers travelling more than they need, is a concept that has been the subject of research since the early 1980s. However, there has been a recent resurgence of interest in this concept, alongside, at least in the UK, with developments in empirical research on the value of time (e.g. [4]). Values of time are used in many policy arenas, particularly in the evaluation of projects for investment appraisal, and are based on the economic theory that travelling time is total disutility suggesting that people only travel in order to "consume" at their destination.

The more recent investigations have centred on identifying whether or not travel is in fact considered as disutility by all travellers and, in some cases, trying to identify the extent of the excess travel. The literature is convincing about the existence of excess travel although definitions vary: the first section of this paper addresses these different definitions before defining a new definition, based on this evidence.

This study acknowledges that excess travel does indeed exist. It is perhaps easier to see how some utility can be achieved when travelling for leisure and there have been some effective quantitative studies in this area which have concentrated on modelling particularly preferences and liking for travel in general and give insights into the desire for travel [8]. This paper is motivated by the current policy 
environment in the UK which is encouraging mode shiftparticularly in the journey to work for example by the "Smarter choices" initiatives supported by Department for Transport. ${ }^{1}$ For many car drivers travelling to work, the commute by public transport is perceived as being longer or more expensive (as they do not recognise the full private and social costs of using a private car) and the investigation of the degree of excess travel in the commute, using Tyne and Wear as a case-study is the focus of the empirical work. A discussion of the case-study characteristics and the sample collected is considered in Section 4.

An underlying aim of this research is to use a better understanding of the nature of excess travel in the commute to develop potential strategies to attract passengers to travel more efficiently and in a more environmentally friendly way using public transport and for this travel to be more productive for them. This requires the identification of commuters exhibiting excess travel and an understanding of the differences between these and commuters who are not excess travelling and this is the focus of the analysis in Section 5. The conclusions are that excess travel is a phenomenon that exists, but on a small scale in the commute to work. People who are excess travelling are not always getting satisfaction from this additional travel and it is necessary to understand the excess traveller profile in terms of the factors they find important and their attitudes towards travel as the foundation to explore how to address this in a policy framework.

\section{The development of excess travel in the current literature}

Excess travel has been defined in transport literature by various researchers. Table 1 below presents different factors have been identified as influencing excess travel in the transport literature. King and Mast [5] focused on travel on US highways and defined excess travel as "the arithmetic difference between total actual highway use, exclusive of destination-free "pleasure" driving, and the use that would have resulted if all such travel had been made by using optimum route connecting each individual origin-destination pair". They suggested that this phenomenon is caused by a number of different factors relating to route selection (either in the highway information system or through route following skills) acting singly or in combination.

In the context of travel to work studies, excess travel was first discussed by Hamilton in 1982. This paper considered monocentric models of urban form and compared commuting time in Japan and US and concluded that both: geography and topography play an important role leading

\footnotetext{
${ }^{1}$ www.gosmarter.co.uk for Tyne and Wear
}

Table 1 Factors identified as causing excess travel in the literature

\begin{tabular}{|c|c|}
\hline Author & Factors causing excess travel \\
\hline Hamilton [2] & $\begin{array}{l}\text { Topography of cities } \\
\text { Multiworker household } \\
\text { Heterogeneous housing \& jobs } \\
\text { Other travel } \\
\text { Travel time v. distance }\end{array}$ \\
\hline King and Mast [5] & $\begin{array}{l}\text { Route selection } \\
\text { In the highway information system } \\
\text { Route following skills } \\
\text { Route planning } \\
\text { Efficiencies in necessary route planning } \\
\text { information }\end{array}$ \\
\hline Merriman et al. [7] & $\begin{array}{l}\text { Multiworker HH ("multiple-worker families") } \\
\text { Tax subsides to transport cost }\end{array}$ \\
\hline Frost et al. [1] & Decentralisation of employees \\
\hline $\begin{array}{l}\text { Mokhtarian and } \\
\text { Salomon [8] }\end{array}$ & $\begin{array}{l}\text { Activities that can be conducted while } \\
\text { travelling } \\
\text { The activity of travelling itself }\end{array}$ \\
\hline Rodriguez [10] & $\begin{array}{l}\text { Spatial choices } \\
\text { Factors at individual scale } \\
\text { Factors at occupational scale } \\
\text { Factors at metropolitan scale }\end{array}$ \\
\hline Ma and Banister [6] & $\begin{array}{l}\text { Multiworker household } \\
\text { Tenancy } \\
\text { Uncertainty of job location } \\
\text { Rapid job turnover } \\
\text { Decreasing importance of commuting } \\
\text { Social factors } \\
\text { Transport policy } \\
\text { Geographical boundaries }\end{array}$ \\
\hline $\begin{array}{l}\text { Horner and } \\
\text { O'Kelly [3] } \\
\text { Jain and Lyons [4] }\end{array}$ & $\begin{array}{l}\text { Context of other activities } \\
\text { The need for transition time }\end{array}$ \\
\hline
\end{tabular}

Source: this research

to Japanese cities having less excess travel because Japanese cities are more compact. He also questioned, given the way in which modern cities have developed, whether the monocentric model was useful as a commuting behaviour predictor. Ma and Banister [6] refer back to the work by Hamilton and use a definition where "excess commuting is the additional journey-to-work travel represented by the difference between the actual average commute and the smallest possible average commute, given the spatial configuration of workplace and residential sites". Frost et al. [1] described excess travel as "the proportion of the actual commuting distance above the optimum" and they also referred to Hamilton's spatial methodology. These all note the importance of a spatial element in defining excess commuting. But there are also authors who focus 
mainly on time and distance variables. Horner and O'Kelly [3] used "the gap between observed commuting and the theoretical minimum commute" as their definition of the phenomenon giving one of the shortest and simplest in literature and most of them use spatial elements as well as time and distance variables.

Rodriguez [10] used a case study of bank tellers in Bogota, Colombia and showed the existence of a link between spatial choices and excess commuting. He splits commuters into two groups which were characterised as being "voluntary" or "involuntary" excess commuters. Involuntary excess commuters are those who "have the desire to reduce it [travel] at the cost of a job relocation", whereas voluntary excess commuters have accepted the amount of travel they do "as a trade off for other benefits". Although Rodriguez focuses on involuntary excess commuting, the distinction between the two groups of commuters highlights the fact that there are some people who prefer longer commuting for some benefits, such as access to local amenities or better accessibility to non-work destinations. He concluded that excess travel could be eliminated if individuals were to relocate so as to minimise their journey to work.

In a qualitative travel study, Jain and Lyons [4] asked people about their willingness to travel more than they do now. A number replied that if in the future travel would be more attractive they would be prepared to travel more than they do now. They also notice that "travel environments become more equipped" which confirms that some people put some effort in travel preparation process. This element will be incorporated in the defining of a new definition of excess travel in the next section.

All above definitions of excess travel have some spatial element and underline the difference between optimum travel distance and the real distance travelled by individual. Empirical studies have used a number of methodologies to investigate the phenomenon of excess travel using a number of different countries as contexts. These are summarised in Table 2 which is ordered chronologically. Methodologies that have been used include an investigation of actual trips (between origin and destination) and staged trips (which include more than one route) using primary data collected for the study. Other studies have used route mapping, simulations or secondary data to provide results. Table 2 shows that the research identifies a wide variety of results. It can also be seen that whilst many of the authors consider excess travel in terms of distance and time, the most recent studies are largely based in the US and these consider only distance with the notable difference of Ma and Banister [6] looking at Seoul. Another noticeable feature for those studies looking at both excess distance and excess time is that the earlier studies have higher percentage excess time whereas the later ones have higher excess percentage distance.
The empirical research referred to in Table 2 used a number of different definitions. Definitions used additional distance, additional time or both with some, but not all, including space as a variable. However, the public transport literature-specifically the recent literature investigating public transport use identifies that effort is a consideration for passengers $[4,11]$. Indeed Stradling [11] has gone further with a classification of different types of effort when undertaking journeys: physical effort, cognitive effort and affective effort. The public transport literature also identifies that a public transport trip is made up of parts with the time spent accessing and regressing the vehicle imposing higher costs on the traveller than the time spent in-vehicle and with further penalties being imposed if a change of mode or vehicle is required (the interchange penalty). A better definition of excess travel should take into account these developments in the literature. Moreover none of the above studies have acknowledged that an individual might travel further or spend longer travelling because the journey is cheaper. In summary, the literature which has developed the concept excess travel and the empirical studies which have tried to assess its impact have not systematically considered that money and effort might also influence travel choices. A new and extended definition which informs the empirical investigation reported in this paper is discussed in the next section.

\section{A new definition of excess travel}

The excess travel definitions in the previous section have shown many similarities but without specifically considering cost or effort of travel as factors with importance equal to time or distance. The new definition developed by this research builds on this earlier research by including these factors of particular importance to public transport travel into the definition. The new definition is similar to the concept of "voluntary excess travel" discussed by Rodriguez [10] but includes in this a potential role for money and effort. The full definition (presented graphically on Fig. 1) is as follows:

Travel, which is a process of moving from the origin to the destination point so as to consume something at the destination, involves money, time and effort. For one origin and destination pair, there may be different ways of making the journey and the individual will choose a combination of the above variables that minimises the effect of travel on them. If money is constrained a slow but cheaper journey might be chosen over a fast but more expensive journey. A journey that is without interchange might be chosen 
Table 2 Summary of literature on excess travel research

\begin{tabular}{|c|c|c|c|c|c|c|}
\hline Author & $\begin{array}{l}\text { Year } \\
\text { published }\end{array}$ & Study area & Trip purpose & $\begin{array}{l}\text { Mean } \\
\text { excess } \\
\text { Distance } \\
{[\%]}\end{array}$ & $\begin{array}{l}\text { Mean } \\
\text { excess } \\
\text { Time }[\%]\end{array}$ & Comment \\
\hline Jansen & 1966 & San Francisco, US & Work & +5.7 & +9.8 & \\
\hline Orman & 1967 & San Francisco, US & Work & +3.1 & +5.3 & \\
\hline Gordon and Wood & 1969 & Suburban Washington, US & $\mathrm{n} / \mathrm{a}$ & +47.0 & +135.2 & \\
\hline Shepperd and Adams & 1971 & England & $\mathrm{n} / \mathrm{a}$ & +18.9 & & \\
\hline Danbolg and Wallder & 1972 & Vesteras, Sweden & Various & +6.4 & & \\
\hline Tagliacozzo and Pirzio & 1973 & Rome, Italy & $\mathrm{n} / \mathrm{a}$ & +13.2 & +33.0 & \\
\hline Wright & 1976 & Central London, England & Not determined & +5.5 & & $13.1 \%$ excess crossings \\
\hline Morrison & 1977 & England & $\mathrm{n} / \mathrm{a}$ & & +10.3 & \\
\hline Lunn & 1978 & England & $\mathrm{n} / \mathrm{a}$ & +23.7 & +29.4 & \\
\hline Jeffrey and Taylor & 1979 & England & Various & Plus $7.2 \%$ & eneralised cost & \\
\hline Kobayashi & 1979 & Tokyo, Japan & All & & +6.0 & \\
\hline Bovy & 1981 & Eindhoven, Netherlands & Work to home & +7.2 & +13.2 & \\
\hline Hamilton & 1982 & $\begin{array}{l}14 \text { US cities and } \\
27 \text { Japanese cities }\end{array}$ & Work & +87.1 & +70.0 & \\
\hline Mast and Lareau & 1984 & Suburban Washington, US & $\mathrm{n} / \mathrm{a}$ & +150 & & \\
\hline White & 1988 & 25 US cities & Work & & +11.1 & \\
\hline Hamilton & 1989 & Boston, US & Work & +47.1 & & \\
\hline Cropper and Gordon & 1991 & Baltimore, US & Work & +50.0 & & \\
\hline Thurston and Yezer & 1991 & 14 US cities & Work & +32.7 & & \\
\hline Small and Song & 1992 & Los Angeles, US & Work & 69.1 & 65.9 & \\
\hline Hiuliano and Small & 1993 & Los Angeles, US & Work & +53.3 & +50.1 & \\
\hline Kim & 1995 & Los Angeles, US & Work & & +38.7 & \\
\hline Merriman & 1995 & Tokyo, Japan & Work & & +15.0 & \\
\hline Song & 1995 & Los Angeles, US & Work & +53.1 & & \\
\hline Scott & 1997 & Hamilton, US & Work & & +73.14 & \\
\hline Frost et al. & 1998 & 10 UK cities & Work & +19.1 & & \\
\hline Chen & 2000 & Taipei, Taiwan & Work & +79.9 & & \\
\hline Mokhtarian & 2001 & San Francisco, US & Various & - & - & $\begin{array}{l}50 \% \text { of the sample } \\
\text { engaged in desire to } \\
\text { travel for its own sake }\end{array}$ \\
\hline Horner & 2002 & 26 US cities & Work & +46.8 & & \\
\hline Buliung and Kanaroglou & 2002 & Toronto, Canada & Work & +65.0 & & \\
\hline Horner and Murray & 2002 & Boise, US & Work & +26.2 & & \\
\hline Manning & 2003 & London, UK & Work & +55.0 & & \\
\hline Rodriguez & 2004 & Bogota, Colombia & Work & +47.0 & & \\
\hline \multirow[t]{2}{*}{ O'Kelly and Lee } & 2005 & Boise, US & Work & +47.7 & & \\
\hline & & Wichita, US & Work & +55.7 & & \\
\hline Ma and Banister & 2006 & Seoul, South Korea & Work & +51.3 & +30.2 & \\
\hline Niedzielski & 2006 & 4 Polish cities & Work & +47.95 & & \\
\hline
\end{tabular}

Adapted from King and Mast [5] and Ma and Banister [6]

over a faster journey with interchange. Excess travel is when the journey chosen is either more expensive but slower than an alternative (Fig. 1, option A) or needs more effort than an alternative journey costing the same and taking the same time (Fig. 1, option B) or is more expensive, more distant and more timeconsuming than an alternative (Fig. 1, option C). Taking longer but costing the same or more is a way of saying that the individual must be deriving some utility from the travel itself and not just from 

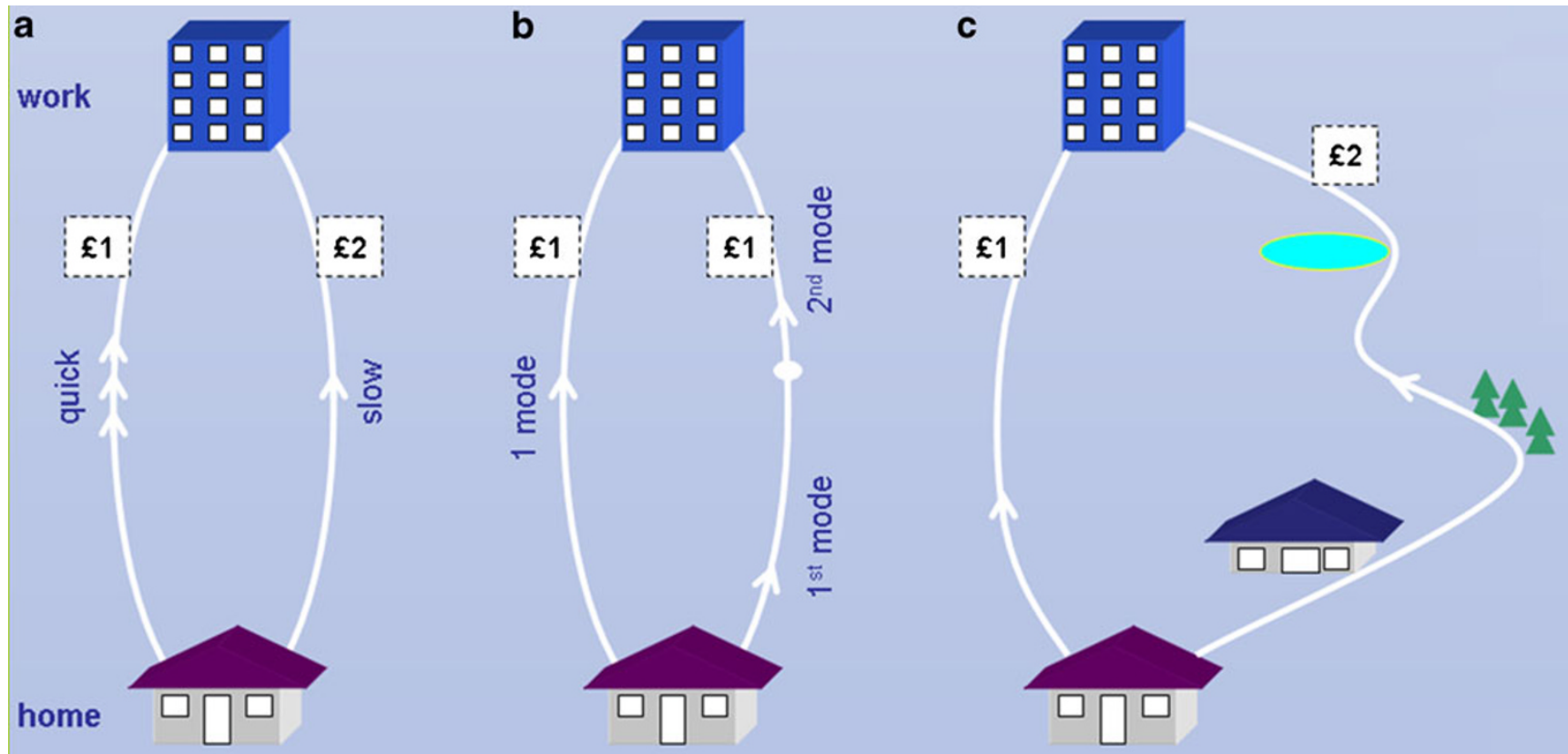

Fig. 1 Examples of excess travel options. Source: This study

whatever is to be consumed at the destination and can arise from an enjoyment or affinity for travel.

According to the above definition excess travel occurs when it is a conscious decision, not derived necessity. Forced need of more time-consuming journey i.e. because of a traffic jams or longer route i.e. because of a bad road signs condition or location is not treated as excess travel in this research.

This definition was used in the survey analysis, after data obtained from paper and online travel to work questionnaires were collected in 2008 .

\section{Methodology}

\subsection{Sample size and sample selection}

This section discusses the collection of data in Tyne and Wear. Tyne and Wear County is located in the North East of England. There are five local authorities within this County and the total population was over 1 million in 2001 [13]. When comparing the County with the whole England, there are some differences related to travel to work. Results presented in Table 3 show clearly that Tyne and Wear has much higher proportion of households with no car/van $(41.8 \%)$ than England as a whole $(26.8 \%)$, and, as a consequence, less people is driving to work $(58.7 \%)$ and more is using public transport $(21.1 \%)$ and walking $(9.6 \%)$. No city or region is ever likely to replicate exactly the population characteristics of a nation and Tyne and Wear is no exception. However Tyne and Wear is a good example of a medium sized regional area with good transport opportunities in which the concept of excess travel can be explored.

Nexus (www.nexus.org.uk) is the Tyne and Wear Passenger Transport Executive (PTE) and looks after the public transport network which includes bus links, ferry, rail and metro. The PTE plans public transport and administers funds for subsidy on behalf of the Passenger Transport Authority (PTA). Tyne and Wear Metro (Fig. 2) is a light rail system with 60 stations linking the five main cities in the county: Newcastle upon Tyne, Gateshead, North Shields, South Shields and Sunderland. First section of the metro system was opened in 1980 and the most recent station in 2008. Bus links are provided by three main bus operators (Stagecoach, Go North East and Arriva) and a number of smaller bus and taxi companies. Ferry crossings across the River Tyne links North Shields with South Shields. All these transport modes build a well integrated transport system for Tyne and Wear.

In order to identify excess travel in the daily commute, two contrasting strategies were employed. The first was to select individuals by their origin: for this, census data was used at the most disaggregated level of the Super Output Level, (SOA) together with Geographical Information System analysis (GIS) to identify "hotspots" which met a number of criteria. The criteria considered were that there should be high proportion of people travelling to work (and by implication, therefore, low proportions of retired people and people working from home), good access to public transport with at least average, for Tyne and Wear, access to 
Table 3 Census 2001 figures for England, Tyne and Wear and Walkerville area

\begin{tabular}{llll}
\hline Census 2001 question & England [\%] & Tyne and Wear [\%] & Walkerville [\%] \\
\hline Households with no car/van [\%] & 26.8 & 41.8 & 29 \\
Travel to work by car [\%] & 61 & 58.7 & 52 \\
Travel to work by public transport [\%] & 14.9 & 21.2 & 22 \\
Travel to work on foot [\%] & 10 & 9.6 & 6 \\
Males & 49 & 48 & 48 \\
Females & 51 & 52 & 52 \\
Age: $16-24$ years old & 10.9 & 11.8 & 9.1 \\
Age: $25-44$ years old & 29.3 & 28.5 & 22.1 \\
Age: $45-64$ years old & 23.8 & 23.5 & 25.5 \\
\hline
\end{tabular}

Source: Census 2001

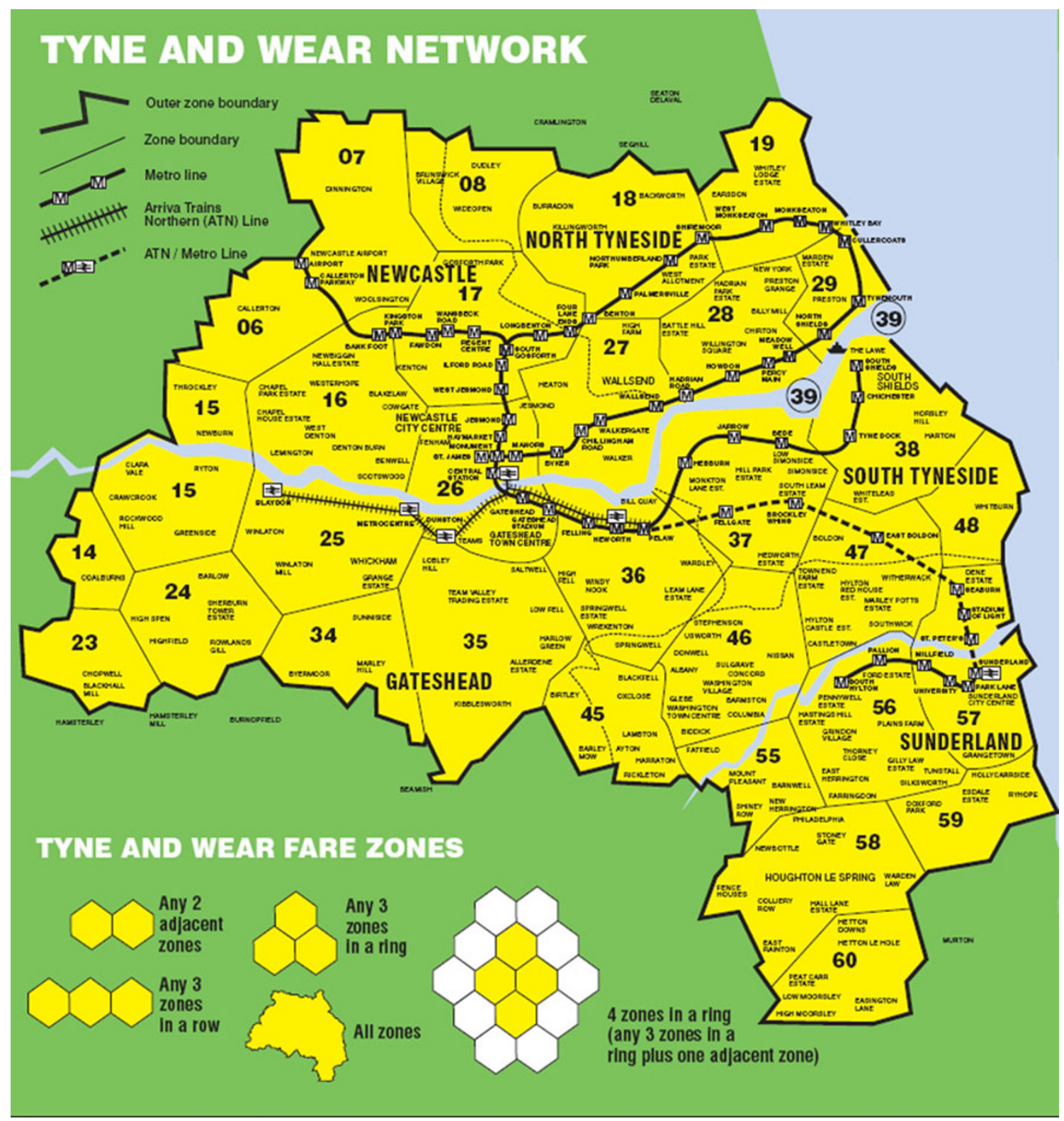

Fig. 2 Tyne and Wear metro map. Source: www.nexus.org.uk 
car. These criteria were designed to maximise the number of people likely to travel and to maximise the options for travel. Six SOAs met these criteria best and are shown on Fig. 3. Geographical localisation, suggested that Walkerville (Fig. 3, area A) and Wallsend (Fig. 3, areas B, C, D, E) would be good study areas since they had good bus and metro links with the city (Fig. 2) but Walkerville had better metro access than other areas. Area $\mathrm{F}$ was identified as meeting all the requirements as well, but the new metro line was opened to Sunderland after the census data was collected in 2001, there was a probability that travel-towork data collected in 2008 would be very different from the 2001 data which is used as a reference base. This suggested that Walkerville was the best area for survey.

In May 2008, 210 paper questionnaires were delivered to every third household (34\%) in the Walkerville area (Newcastle upon Tyne 020D, Lower Layer Super Output
Area) within the light blue area shaded on Fig. 4 in which the main transport links are highlighted. This area consists of 606 households, 1,494 residents and 551 cars [13]. After 2 weeks from first questionnaire delivery, 200 reminder cards were delivered to the same households again. Response rate was poor from the first delivery ( 27 returned) and so an extra 70 copies of the questionnaire were distributed in early June (reaching $46 \%$ households in total), again within this shaded area. In total, 63 questionnaires were returned giving an overall $22.5 \%$ response rate of which 45 full completed questionnaires were useful for analysis.

The second strategy was to investigate individuals at their working destination. An on-line version as well as paper versions of the questionnaire was made available to the potential respondents. The staff from the School of Geography, Politics and Sociology (GPS) at Newcastle

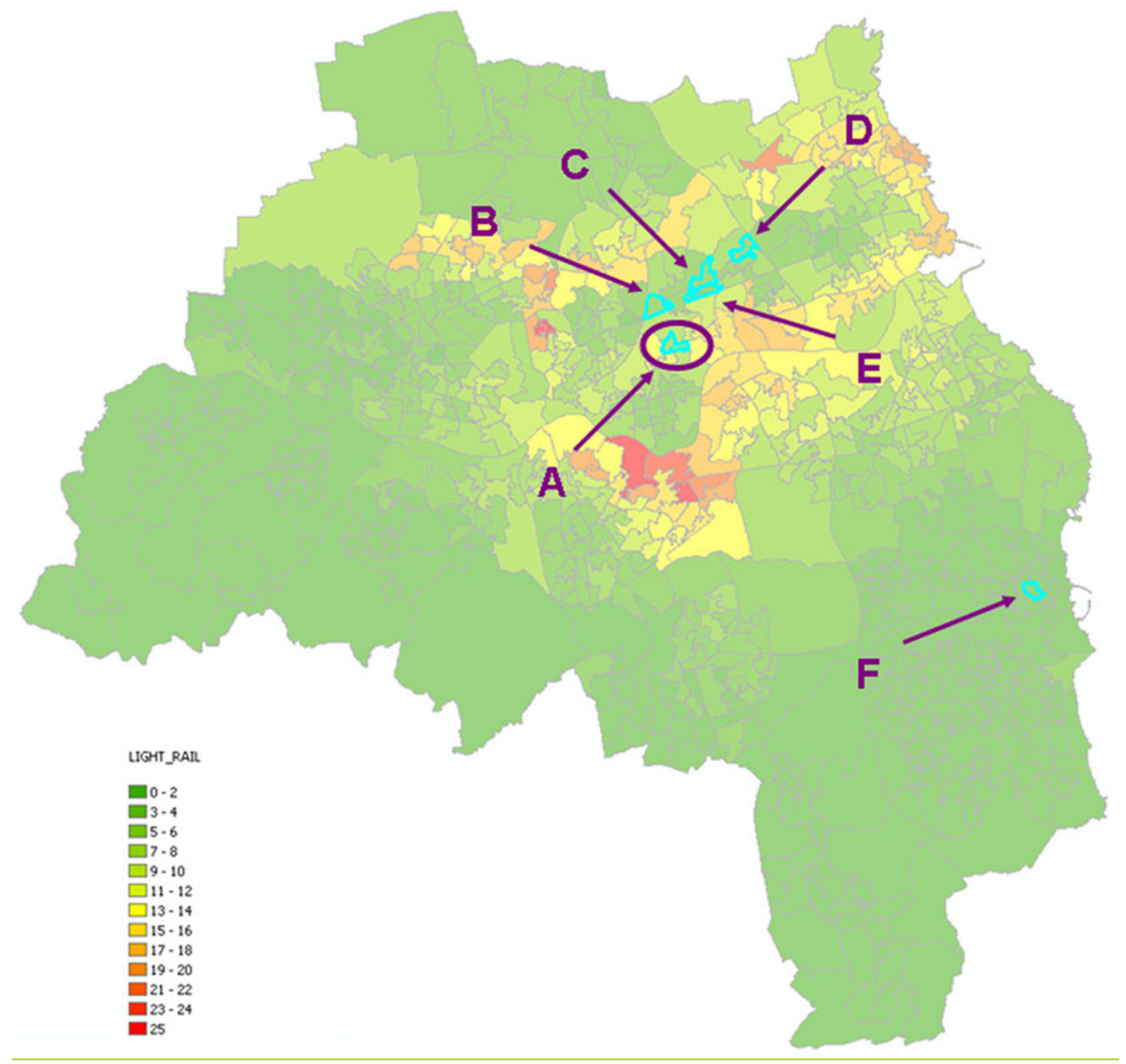

Fig. 3 Map of Tyne and Wear and six final SOA selected, \% of people travelling to work by light rail (metro). Source: data collected from Census 2001 
Fig. 4 Map of Walkerville and transport links (bus stops-red dots, metro line-black line and main roads). Source: this study

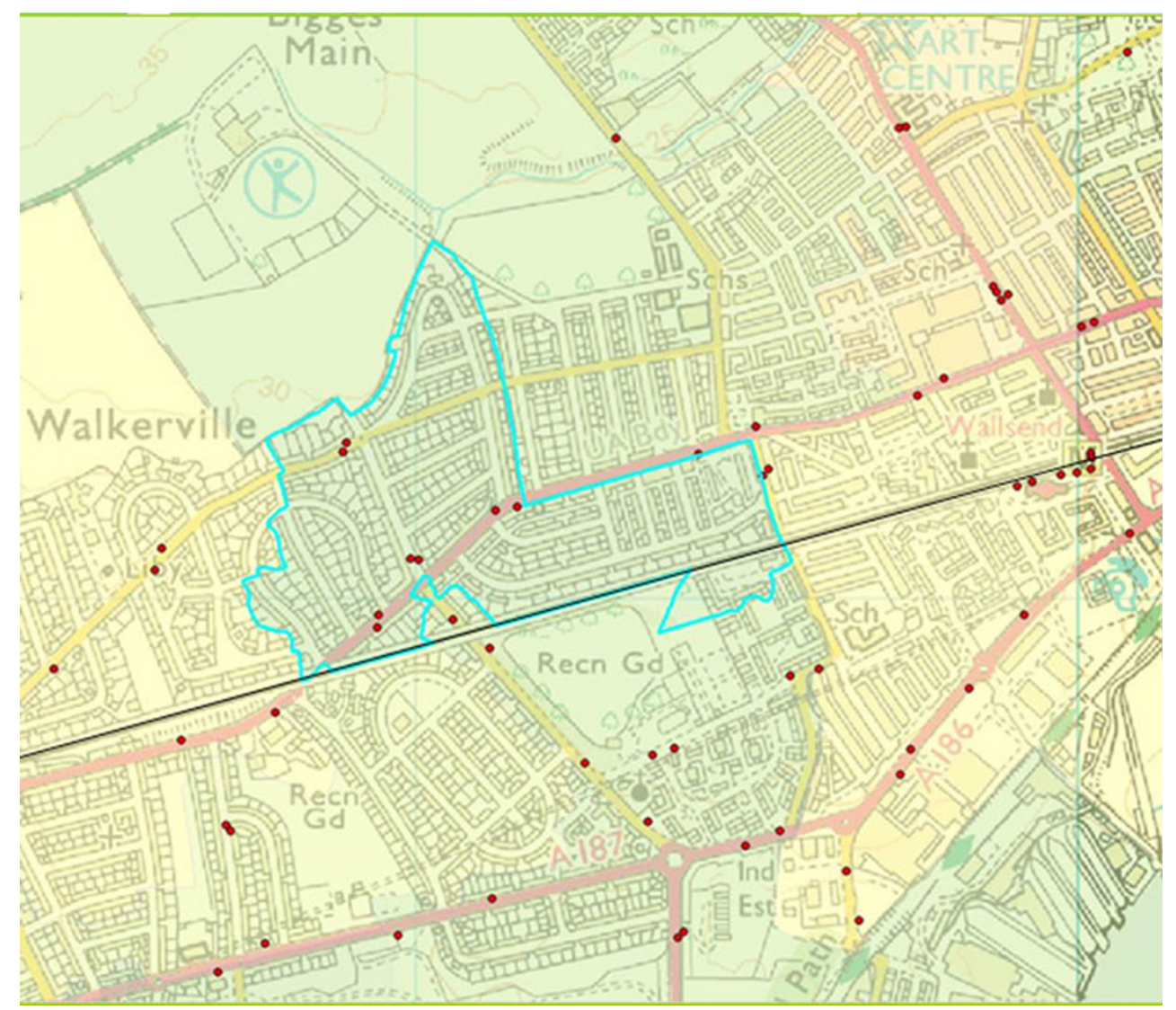

University (all staff, academic, clerical and other employees were included) were selected, because within this School the number of employees was bounded at about 100 people with the majority working from a single site and its location on the University campus meant that it had good transport links with the city. The total number of the questionnaires completed by these employees was 42 (35 online and seven hard copies) giving a response rate of approximately $45 \%$ (approximate as the exact number of staff is not known: some staff are shared between different parts of the University). Forty of the questionnaires were completed and useful.

Overall, therefore, this study had access to over 100 returns in total with 85 fully completed and useful questionnaires. The nature of this sample is discussed in the next sub-section.

\subsubsection{Description of the sample}

The total number of returned questionnaires was 105 , but only 85 were usable, and included 45 residents from Walkerville area and 40 employees from the School of GPS. Socio-economic characteristics of the total sample and two sub-samples are presented in Table 5.

As a result of the way in which the data has been collected, only the Walkerville sample can be compared to the Tyne and Wear population as the characteristics of the population of employees in the School of GPS are not known. These are presented in Table 4 and show that nearly double the number of females over males took part in the survey whereas the numbers of each are more or less equal in the population. The fact that there are more female respondents will cause some bias, especially as other evidence [9] suggests that on public transport there are a higher proportion of female users. Future research will need to address the extent of the bias and how this can be reduced through questionnaire delivery or design. Overall, of the respondents were aged between 24 and 64 years old (93\%), married (64\%) and working in higher or lower managerial positions $(48 \%)$. The Walkerville sample is much older and includes 31 respondents $(69 \%$ of total Walkerville sample) between 41 and 64 years old as compared to the University sample where 24 respondents (60\% of total GPS sample) are aged between 24 and 40 . Most of the individuals from both samples are married (Walkerville: 32 respondents $=38 \%$; GPS: 22 respondents $=$ $26 \%$ ) and the number of people in Higher and Lower Managerial positions is similar in both samples. There are however more clerical staff workers in the Walkerville sub-sample $(16 \%)$ and more students in University subsample (11\%). Most of the respondents have a driving licence and at least one car in the household but there is a large difference in the number of households without cars 
Table 4 Values of attributes for six SOA considered for sampling

\begin{tabular}{|c|c|c|c|c|c|c|c|c|c|}
\hline Attribute & Value of criteria & $\operatorname{Min}^{\mathrm{a}} \%$ & $\operatorname{Max}^{\mathrm{a}} \%$ & A & B & $\mathrm{C}$ & $\mathrm{D}$ & $\mathrm{E}$ & $\mathrm{F}$ \\
\hline Retired & Low & 2 & 36.2 & 17.1 & 12.1 & 15.2 & 9.1 & 15.6 & 15.8 \\
\hline Unemployed & Low & 0.7 & 15.7 & 2.8 & 4 & 3.3 & 3.2 & 2.4 & 3.4 \\
\hline Sick/disabled & Low & 1.3 & 23.6 & 5.8 & 5.9 & 7 & 5.6 & 6 & 8.9 \\
\hline Working at home & Low & 3 & 15 & 8 & 8 & 7 & 5 & 6 & 6 \\
\hline Working part-time & High & 1.8 & 16.9 & 14.2 & 12.8 & 13.5 & 13.2 & 15 & 11.5 \\
\hline Working full-time & High & 7.8 & 62 & 40.5 & 47.9 & 43.9 & 51.7 & 42.3 & 45.5 \\
\hline Student & High & 1 & 62.8 & 3.8 & 2.7 & 3 & 3.4 & 4.3 & 2.9 \\
\hline 0 car in $\mathrm{HH}$ & Low & 4 & 84 & 29 & 28 & 34 & 28 & 31 & 34 \\
\hline Travel to work-metro & High & 0 & 25 & 5 & 3 & 2 & 3 & 1 & 0 \\
\hline Travel to work-bus & High & 1 & 38 & 17 & 17 & 18 & 16 & 19 & 16 \\
\hline Travel to work-driving & High & 21 & 74 & 52 & 52 & 51 & 54 & 52 & 52 \\
\hline Travel to work - passenger in a car & High & 2 & 16 & 10 & 10 & 11 & 11 & 10 & 10 \\
\hline
\end{tabular}

${ }^{a}$ min and max value of percentage for the attribute in census 2001 data

Source: Census 2001

with $2 \%$ in Walkerville and $12 \%$ at the School of GPS at the University (which is much lower than in the population as a whole). The Walkerville sub-sample reflects the way in which it was collected with the Walkerville area being chosen subject to criteria of which one was a low number of households without cars. The characteristics of the Walkerville sample, close to those characteristics reported by the Census 2001 data, confirm that sample selection by using GIS was efficient. It should however be noted that the census information was collected at least 7 years before this data collection and therefore some differences between self-reported results and figures from Census 2001 might be anticipated (Table 5).

\subsection{Analysis}

All respondents were asked in the questionnaire to report their origin and destination points when travelling to work. They also described in details the last journey to work, including time, cost, and step-by-step transport modes and times, so that this data could be used in later analysis and comparisons. Knowing the postcodes of origins and destinations for all respondents, the Public Transport Options (PTOs) were compared with each Self Reported (SR) option in two ways. First, in terms of 'pure' time and cost, described in 4.2.1 below. A second approach, using generalised cost, where the travel time is weighted according to activity was employed as an alternative and this is described in the following section 4.2.2. Detailed observations are made of these alternative methodologies in section 5 .

\subsubsection{Method 1: 'pure' time and cost}

In this approach, four variables were considered: time, distance, cost and effort. Although there was no direct question in the questionnaire exploring the effort involved in their travel, this was approximated from the detailed step-by-step description of the last journey from home to work. SR times and costs of travel were compared with times and costs of two PTOs for the same origin-destination pairs where the prices for the PTO options were cost first on the basis of an annual ticket and second on a daily ticket being available for travel.

\subsubsection{Method 2: generalised cost}

The second alternative was to use a generalised cost definition to compare SR travel and the two proposed PTO. This was based on the methodology outlined by the UK Department for Transport (www.webtag.org.uk) for travel by public transport (bus, metro or train) and used the following formula for travel by public transport.

$G_{P T}=V_{W K} \cdot A+V_{W T} \cdot W+T+\frac{F}{V O T}+I$

Where A is the total walking time to and from the service, $\mathrm{W}$ is the total waiting time for all services used on the journey, $\mathrm{T}$ is time spent on the service (bus, train), $\mathrm{F}$ is the fare and $\mathrm{I}$ is the interchange penalty. $\mathrm{V}_{\mathrm{wk}}$ and $\mathrm{V}_{\mathrm{wt}}$ are weights for walking and waiting. VOT is a value of time for a specific transport mode.

\section{Results}

There were 65 respondents, from the fully completed questionnaires that totalled 85 , who reported both origin and destination postcodes (home and work) which allowed these calculations to be made. The analysis aims first to 
Table 5 Socio-economic characteristics of the pilot sample (total sample size 85 respondents)

\begin{tabular}{|c|c|c|c|c|}
\hline Category & Option & $\begin{array}{l}\text { Walker-ville } \\
{[\% \text { of total sample] }} \\
n=45\end{array}$ & $\begin{array}{l}\text { School of GPS } \\
{[\% \text { of total sample }]} \\
n=40\end{array}$ & Total $[\%]$ \\
\hline \multirow[t]{3}{*}{ Gender } & Male & 16 & 14 & 31 \\
\hline & Female & 34 & 33 & 67 \\
\hline & No response & 2 & 0 & 2 \\
\hline \multirow[t]{5}{*}{ Age } & 23 or younger & 2 & 2 & 5 \\
\hline & $24-40$ & 12 & 28 & 40 \\
\hline & $41-64$ & 36 & 16 & 53 \\
\hline & $65-74$ & 1 & 0 & 1 \\
\hline & 75 and older & 1 & 0 & 1 \\
\hline \multirow[t]{3}{*}{ Marital status } & Single (never married) & 8 & 19 & 27 \\
\hline & Married or re-married & 38 & 26 & 64 \\
\hline & Separated or divorced & 7 & 2 & 9 \\
\hline \multirow[t]{6}{*}{ Economic activity } & Higher and lower managerial and professional & 25 & 24 & 48 \\
\hline & Supervisor, production worker, skilled trade & 5 & 1 & 6 \\
\hline & No response & 1 & 1 & 2 \\
\hline & Clerical, retail staff & 16 & 6 & 22 \\
\hline & Student & 1 & 11 & 12 \\
\hline & Occupations not stated or inadequately described & 5 & 5 & 9 \\
\hline \multirow{5}{*}{$\begin{array}{l}\text { Number of people } \\
\text { living in household }\end{array}$} & 1 person & 4 & 7 & 11 \\
\hline & 2 people & 20 & 20 & 40 \\
\hline & 3 people & 15 & 12 & 27 \\
\hline & 4 people & 8 & 8 & 16 \\
\hline & 5 or more people & 6 & 0 & 6 \\
\hline \multirow[t]{2}{*}{ Driving licence } & yes & 42 & 38 & 80 \\
\hline & no & 11 & 9 & 20 \\
\hline \multirow{4}{*}{$\begin{array}{l}\text { Number of cars or } \\
\text { vans in household }\end{array}$} & none & 2 & 12 & 14 \\
\hline & 1 car & 31 & 22 & 53 \\
\hline & 2 cars & 18 & 11 & 28 \\
\hline & 3 cars & 2 & 2 & 5 \\
\hline
\end{tabular}

Source: this study

identify excess travellers from the total sample, according to the new definition presented in Section 3 and, if the existence of excess travellers is confirmed, to analyse their responses and profiles in comparison to non-excess travellers.

For each respondent, for whom an origin and destination was available, two public transport options were identified using the network of public transport services in Tyne and Wear. The two quickest public transport options for origindestination postcodes were found by using a multi-modal travel planning website supported by the UK Department for Transport and called "Transport Direct" www.transportdirect. info (June 2008) which gave times for each journey. The prices of annual and daily bus tickets were taken from public transport operators' websites (for buses - Stagecoach, Go North East, Arriva; for metro-Nexus, for train-National Express).

For the analysis, a strict adoption of the new definition was used. An amount of $10 \%$ excess (of time and cost) as a minimum was used so that excess time and cost was deemed to occur when the travel is longer in minutes by more than $10 \%$ and more expensive by more than $10 \%$ of the two public transport options identified for each individual. In other words, when two proposed public transport options (PTO) are not more than $90 \%$ of self reported (SR) option, then excess travel in SR option in comparison with PTO1 and PTO2 occurs. When time and cost excesses are present for the same PTO, then the option is considered as an excess travel option.

For example: Respondent 10 reported that their last travel to work took $85 \mathrm{~min}$ and cost $£ 8$. Travel between the same origin and destination points by PTO1 took $59 \mathrm{~min}$ and cost $£ 5.49$ and by PTO2 $67 \mathrm{~min}$ and £4.25. Both PTOs were less than $90 \%$ of SR option and Respondent 10 is therefore excess travelling in both time and cost (this is expanded in more detail in the next section). 


\section{1 "Pure" time and cost analysis}

"Pure" time and cost analysis has been undertaken for all 65 respondents. SR times and costs were compared with the calculated figures for two proposed PTO. Illustrative results for respondent 10 are shown in Table 6 below.

Clearly the cost of a daily (as opposed to an annual) ticket is higher but turned out to make very little difference to the overall number of excess travellers (six as opposed to five) and the more conservative (using daily tickets) is reported in Fig. 5 below and in the rest of this section. Figure 5 distinguishes between those travellers who were excess time travellers, excess cost travellers and excess time and cost travellers in relation to the comparison of their SR with the two PTO options.

Overall, the analysis using this methodology identified five excess travellers ( $8 \%$ of the sample) when daily ticket prices were used in the comparison with $13 \%$ of the sample being "excess time travellers" and $34 \%$ being "excess cost travellers". Overall, this gives, as a conservative value, five excess travellers from the total sample size of $65(8 \%)$.

\subsection{Generalised cost}

A travel option by car was excluded from this analysis as respondents were not explicitly asked if they had access to a car as an alternative mode (this issue will be addressed by the next questionnaire). As with the pure time and cost methodology, two PTOs were considered for each respondent.

Using this, the results for respondent 10 are shown in Table 7.

In the formula for generalised cost presented in section 4.2.2 there are weights attached to walking time and waiting time. UK Department of Transport [12] recommends using weights between 1.5 and 2.0 for walking time, between 1.5 and 2.5 for waiting time and between 5 and $10 \mathrm{~min}$ for interchange penalty. This study investigated nine different options for weights as shown in Table 8. This showed that the numbers of respondents considered to be

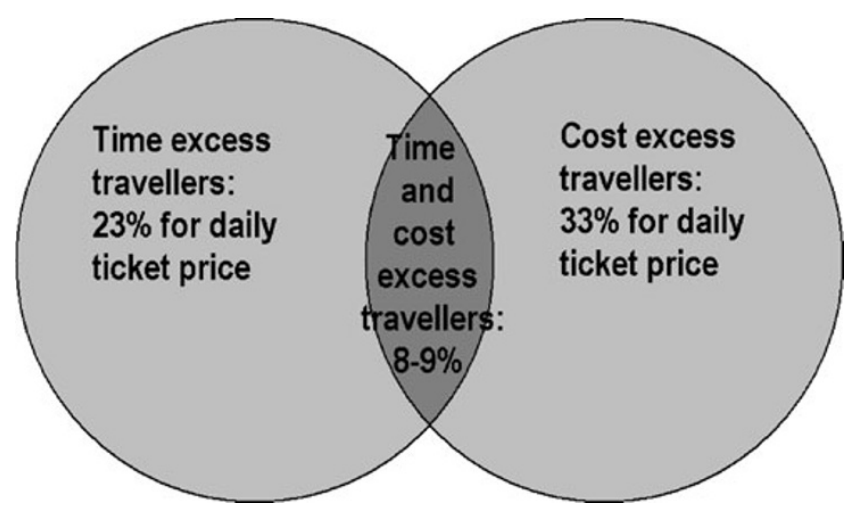

Fig. 5 Three groups of excess travellers. Source: this study

undertaking excess travel declined as the values of weights increased. When the weights were equal to " 1 " for walking and waiting times and " 0 " for interchange penalty, then the number of respondents considered as excess travellers was 15 in time [mins] or 23 in money [£]. When generalised cost is to be considered in money units $[£]$, the final result in time [mins] was multiplied by value of time for the transport mode which the respondent was using (e.g. metro or bus, according to the current values used by the Department of Transport) and this accounts for the differences in the numbers of excess travellers depending on the unit of generalised cost. Table 8 shows that if the different valuations which are typically given to walking and waiting times are ignored as well as assuming away the interchange penalty then this gives the maximum number of excess travellers. More realistically it would be expected to increase the walking and waiting weights and to acknowledge the interchange penalty. At a minimum, this gives three excess travellers measured in minutes ( $4 \%$ of the sample) and eight excess travellers measured in money ( $9 \%$ of the sample).

\subsection{Some observations on the alternative methodologies}

Both methodologies utilised for the identification of the number of excess travellers and the extent to which their
Table 6 Time and cost of SR and PTOs and excess travel results for respondent 10 by using "pure" time and cost method

\begin{tabular}{lllll}
\hline Description & Option & Unit & Respondent number 10 & \% of SR results \\
\hline Self reported option & SR & Time [mins] & 85 & 100 \\
& & Cost [£] & 8 & 100 \\
Annual ticket price & PTO1 & Time [mins] & 59 & 69 \\
& & Cost [£] & 5.49 & 68 \\
& PTO2 & Time [mins] & 67 & 78 \\
Daily ticket price & & Cost [£] & 4.25 & 63 \\
& PTO1 & Time [mins] & 59 & 69 \\
& & Cost [£] & 6.7 & 83 \\
& PTO2 & Time [mins] & 67 & 78 \\
& & Cost [£] & 5.7 & 71 \\
\hline
\end{tabular}

Source: this study 
Table 7 Time and cost of SR and PTO and excess travel results for respondent 10 by using generalised cost method

\begin{tabular}{lllll}
\hline Description & Option & Unit & Respondent number 10 & \% of SR results \\
\hline Self reported option & SR & Time [mins $]$ & 85 & 100 \\
Generalised cost & & Cost $[£]$ & 8 & 100 \\
& SR & {$[$ mins $]$} & 92.46 & 100 \\
& \multirow{2}{*}{ PTO1 } & {$[£]$} & 40.73 & 100 \\
& & {$[\mathrm{mins}]$} & 70.52 & 76 \\
& PTO2 & {$[$ mins $]$} & 33.6 & 82 \\
& & {$[£]$} & 31.46 & 77 \\
& & & 34.05 & 83 \\
\hline
\end{tabular}

Source: this study

travellers" suggests that the identification of these travellers is critically dependent on the criteria used. In all there were five respondents who were identified as excess travellers in most of the cases when implementing both methodologies. The characteristics for these respondents are presented in Table 9. It is interesting to note that all these excess travellers identified cerebral activities as the activity undertaken when travelling to work with only one identifying work specifically. From the total sample size of 85 there were eight respondents $(9 \%)$ who admitted that they do some work when commuting. This very much supports the qualitative work of Jain and Lyons [4].

The most popular transport mode to work in this sample was a car ( $40 \%$ of all respondents) whereas only one excess traveller is driving to work. The other four excess travellers, and $35 \%$ of non-excess travellers, are using public transport. $23 \%$ of respondents are choosing eco-friendly ways to get to work by walking or cycling and none of these were identified as undertaking excess travel.

In the sample as a whole, the shortest journey to work was $5 \mathrm{~min}$ and the longest $120 \mathrm{~min}$. The identified excess travellers are commuting much longer than the average $29 \mathrm{~min}$ for the sample as a whole with four spending more than $50 \mathrm{~min}$ on the journey. Not surprisingly, they believe that they travel "too much" or "far too much". Only one excess traveller, who is travelling $25 \mathrm{~min}$ by bus, is content with the amount of time spent commuting. Although $46 \%$ of the total sample (both excess travellers and non-excess travellers) is commuting less than $20 \mathrm{~min}$, no respondent identified their commute as "too short". Overall $75 \%$ identified the amount of time they spend travelling to work as "about right", and $21 \%$ complained that their commute is too long. Four of the excess travellers suggested an ideal one way commute time would be between 20-30 min, in comparison to the non-excess travellers most convenient would be where this figure was between 10-15 $\min (30 \%)$.

Small number of excess travellers can be explained by a small sample size. But considering the sources where people look for information about local transport options, where $60 \%$ uses Internet, five excess travellers is still a significant figure. 
Table 9 Socio-economic characteristics of five excess travellers

\begin{tabular}{|c|c|c|c|c|c|}
\hline Respondent number & 10 & 22 & 23 & 68 & 77 \\
\hline Last transport mode & Car & Bus & Bus & Bus & Bus \\
\hline Distance travelled $[\mathrm{km}]$ & 35.89 & 11.43 & 13.04 & 6.92 & 53.11 \\
\hline Time [mins] spent commuting & 85 & 65 & 50 & 25 & 105 \\
\hline Cost $[£]$ of commute & 8 & 3.8 & 2.4 & 2 & 5.5 \\
\hline $\begin{array}{l}\text { Identified alternative } \\
\text { transport mode }\end{array}$ & $\begin{array}{l}\text { Metro }+ \\
\quad \text { train }+ \text { walk }\end{array}$ & No response & No response & Metro & Train \\
\hline No of cars in Household & 2 & 1 & 0 & 0 & 1 \\
\hline Driving licence & Yes & No & Yes & No & No \\
\hline Gender & $\mathrm{F}$ & $\mathrm{F}$ & M & $\mathrm{F}$ & M \\
\hline Age & $<23$ & $41-64$ & $41-64$ & $24-40$ & $24-40$ \\
\hline Marital status & Single & Single & Married & Single & Married \\
\hline Economic activity & $\begin{array}{l}\text { Student- } \\
\text { full time }\end{array}$ & $\begin{array}{l}\text { Higher managerial- } \\
\text { full time }\end{array}$ & $\begin{array}{l}\text { Supervisor- } \\
\text { full time }\end{array}$ & $\begin{array}{l}\text { Student- } \\
\text { full time }\end{array}$ & No response \\
\hline No of people in Household & 4 & 2 & 3 & 1 & 2 \\
\hline $\begin{array}{l}\text { If you could arrive at your } \\
\text { work without commuting } \\
\text { would you like to do it? }\end{array}$ & No & Yes & Yes & No & Yes \\
\hline Activities when travelling & $\begin{array}{l}\text { Music, } \\
\text { observe, eat }\end{array}$ & $\begin{array}{l}\text { Think, read, } \\
\text { talk, observe }\end{array}$ & Think, relax & $\begin{array}{l}\text { Think, music, read, } \\
\text { talk, relax, observe }\end{array}$ & $\begin{array}{l}\text { Sleep, think, music, } \\
\text { read, work, relax }\end{array}$ \\
\hline $\begin{array}{l}\text { Amount of time spend } \\
\text { travelling to work is: }\end{array}$ & Too much & Too much & Far too much & About right & Far too much \\
\hline $\begin{array}{l}\text { Ideal one-way commute } \\
\text { time [mins] would be }\end{array}$ & 30 & 30 & 15 & 30 & 20 \\
\hline $\begin{array}{l}\text { Where do you look for } \\
\text { information about local } \\
\text { transport options? }\end{array}$ & Internet & $\begin{array}{l}\text { Press, bus and } \\
\text { metro companies }\end{array}$ & $\begin{array}{l}\text { Local press, } \\
\text { council }\end{array}$ & Internet & $\begin{array}{l}\text { Internet, bus } \\
\text { timetable }\end{array}$ \\
\hline
\end{tabular}

Source: this study

\subsection{Does the excess traveller show different preferences?}

The questionnaire sought respondent's views in terms of the importance of different factors in determining their commute mode and in terms of their reactions to a set of questions designed to elicit attitudes to travel. These were both rated on a Likert scale and are reported in Tables 10 and 11 below.
When comparing the excess travellers to the non-excess travellers, there are many similarities but some key differences. Table 10 illustrates that excess travellers' value of good accessibility is statistically significantly different at the $5 \%$ level from the non-excess travellers and low price and comfort have the same value for the two groups. There are also apparent qualitative differences between the means which are not statistically significantly different, probably
Table 10 Attitudes towards factors influencing travel to work options and mean values (scale: 1 -not important, 5 -very important)

${ }^{a}$ significant at the $5 \%$ level Source: this study

\begin{tabular}{llll}
\hline $\begin{array}{l}\text { Importance of factors when } \\
\text { choosing travel to work }\end{array}$ & $\begin{array}{l}\text { Non-excess } \\
\text { travellers }(n=60)\end{array}$ & $\begin{array}{l}\text { Excess travellers } \\
(n=5)\end{array}$ & $\begin{array}{l}p \text {-value (2 tailed) for } \\
\text { difference of means }\end{array}$ \\
\hline Good accessibility & 4.1 & 4.8 & $.029^{\mathrm{a}}$ \\
Good comfort & 3.6 & 3.6 & .980 \\
Curiosity of new places & 2.2 & 3.4 & .155 \\
Short distance & 3.7 & 3.0 & .309 \\
High independence & 4.0 & 3.8 & .802 \\
Low price & 4.0 & 4.0 & .956 \\
Good safety & 4.4 & 3.8 & .474 \\
Short time & 4.4 & 4.2 & .693 \\
Good enjoyment & 3.5 & 3.0 & .410 \\
\hline
\end{tabular}


Table 11 Statements characterising travel to work and mean values (scale: 1 -not at all true, 2 -not very true, 3 -fairly true, 4 -very true)

\begin{tabular}{|c|c|c|c|}
\hline Statement & $\begin{array}{l}\text { Total } \\
\text { sample } \\
(n=60)\end{array}$ & $\begin{array}{l}\text { Excess } \\
\text { travellers } \\
(n=5)\end{array}$ & $\begin{array}{l}p \text {-value ( } 2 \text { tailed) } \\
\text { for difference } \\
\text { of means }\end{array}$ \\
\hline A travel time is a good time to relax & 2.5 & 1.6 & $.091^{\mathrm{b}}$ \\
\hline A travel time is a good time to think & 3.1 & 3.6 & .122 \\
\hline My trip is a useful transition between home and work/destination & 2.8 & 2.0 & .278 \\
\hline I like travelling alone & 2.7 & 3.0 & .603 \\
\hline I think travel is boring & 2.2 & 3.0 & $.066^{\mathrm{b}}$ \\
\hline My trip is a real hassle & 1.9 & 2.8 & .186 \\
\hline We need more public transportation, even if taxes have to pay for a lot of the costs & 2.8 & 3.6 & $.020^{\mathrm{a}}$ \\
\hline I think about climate change/other environmental issues when making travel choices & 2.6 & 1.8 & $.100^{\mathrm{b}}$ \\
\hline If I could find quicker and cheaper way I would use it & 3.1 & 3.8 & $.021^{\mathrm{a}}$ \\
\hline
\end{tabular}

${ }^{a}$ significant at the $5 \%$ level; ${ }^{b}$ significant at the $10 \%$ level

Source: this study

due to the small sample size of excess travellers, which need to be explored in a larger sample. In particular it appears excess travellers find the curiosity of new places as an important factor in making their commuting decision.

In general excess travellers feel more negative about the travel to work than the whole sample. Their responses on the attitudinal questions are statistically different from nonexcess travellers on their attitude towards public transport (although this could be a reflection of the high proportion of public transport users in this sub-sample) and finding a quicker and cheaper way to travel at the $5 \%$ level of significance and on the relaxing and boring nature of travel at a $10 \%$ level of significance. Excess travellers are not as worried about the climate change or the environment as the whole sample when travelling. It is particularly interesting that excess travellers have a higher mean score on the attitude 'If I could find quicker and cheaper way I would use it' which suggests that not all the excess travellers are excess travellers by choice.

\section{Conclusions}

Excess travel in the literature has a long history but has not matured to give a single definition with which to compare different empirical studies which have focussed both on leisure and commuting. Moreover, whilst there have been many empirical studies, these have used definitions which have not been based on current understanding of the public transport literature where it is recognised that different stages of a public transport journey carry different weights for the passenger and that interchange and travelling generally involves effort. This paper proposes a new definition which builds on the literature and incorporates the recent under- standing of the public transport literature to provide a sound foundation on which to base empirical investigation.

Methodologically, the sample selection using a combination of census and GIS to identify "hotspots" was efficient at identifying an appropriate sample with the desired attributes which, in particular, allowed a variety of destinations to be examined. In some ways this is a better way to sample than the use of destination base data as it is easier to control for the socio-economic profile of the sample. Two methodologies were explored to identify excess travellers: there is a preference for the methodology which allows effort, an important part of the new definition, to be explicitly valued. However, this methodology is constrained by the need to use weights and valuations which although validated, do add an element of subjectivity.

The results identify that a small proportion of the sample can be defined as excess travelling, irrespective of the methodology used for calculation. The alternative options for the same journey for excess travellers being between 60 and $80 \%$ of the self reported option, depending on whether time or cost is being used as the measurement. In terms of comparing the excess travellers with non-excess travellers, some statistically significant differences were identified, despite the small sample size. In particular the role of good accessibility in choosing their travel to work options. There were also statistically significant differences in attitudes to travel.

Whilst the sample size is small, this paper contributes by confirming that excess travelling exists in the commute to work and provides a start in the understanding of differences between excess and non-excess travellers in terms of the factors which are cited as important for the journey and in their perceptions of travel. A better understanding of who the excess travellers are and why and how they behave in 
their daily commute is the foundation for exploring policy to encourage sustainable transport patterns of commuting. That, in the future, will allow developing potential strategies for public transport providers in the marketing of excess travel time into activity time as a way of creating extra revenue for PTPs.

Open Access This article is distributed under the terms of the Creative Commons Attribution Noncommercial License which permits any noncommercial use, distribution, and reproduction in any medium, provided the original author(s) and source are credited.

\section{References}

1. Frost M et al (1998) Excess or wasteful commuting in a selection of British cities. Transp Res Part A Policy Pract 32(7):529-538

2. Hamilton BW (1982) Wasteful commuting. J Polit Econ 90 (5):1035-1053

3. Horner MW, O'Kelly ME (2007) Is non-work travel excessive? J Transp Geogr 15:411-416
4. Jain J, Lyons G (2007) The gift of travel time. J Transp Geogr. doi:10.1016/j.trangeo.2007.05.001

5. King GF, Mast TM (1987) Excess travel: causes, extent, and consequences. Transport Research Record 1111:126-134

6. Ma K, Banister D (2006) Excess commuting: a critical review. Transp Rev 26(6):749-767

7. Merriman D et al (1995) Excess commuting in the Tokyo metropolitan area: measurement and policy simulations. Urban Stud 32(1):69-85

8. Mokhtarian P, Salomon I (2001) How derived is the demand for travel? Some conceptual and measurement considerations. Transp Res A 35(8):695-719

9. Pickett MW, Gray SM (1996) The effectiveness of bus-based park \& ride. TRL Report 207, Transport Research Laboratory. Crowthorne, Berkshire

10. Rodriguez DA (2003) Spatial choices and excess commuting: a case study of bank tellers in Bogota, Colombia. J Transp Geogr 12:49-61, 2004

11. Stradling SG (2002) Transport user needs and marketing public transport. Munic Eng 151(1):23-28

12. UK Department for Transport (2006) http://www.webtag.org.uk Accessed in May 2007

13. UK National Statistics (2001) Census 2001, http://neighbourhood. statistics.gov.uk. Accessed May 2007 